\title{
Crescimento tumoral e relação com o estado caquético em ratos adultos.
}

\author{
Sabrina Y. Odo Rocha (IC), Maria Cristina C G Marcondes (PQ).
}

\begin{abstract}
Resumo
A caquexia relacionada ao câncer é uma síndrome compreendendo variados sintomas e sinais, levando os pacientes a considerável perda de peso. Apesar do tratamento ainda depender de variações do estado do paciente e também da característica particular de cada tipo de neoplasia, é relevante os estudos aplicados à síndrome câncer-caquexia em modelos experimentais para que assim possamos ter um melhor entendimento das respostas do hospedeiro e também das células neoplásicas.
\end{abstract}

Palavras chave: Caquexia- câncer, Tumor Walker 256, Taxa Metabólica.

\section{Introdução}

Câncer é o nome dado a um conjunto de doenças que têm em comum o crescimento desordenado de células que invadem os tecidos e órgãos, podendo espalhar-se para outras regiões do corpo. Dividindo-se rapidamente, estas células são muito agressivas e incontroláveis, determinando a formação de tumores ou neoplasias malignas. Segundo o Instituto Nacional do Câncer (INCA), o câncer é hoje uma patologia que corresponde à segunda causa de morte no Brasil, e dados da Organização Mundial de Saúde (OMS) mostram que é a segunda doença que mais mata no mundo, perdendo apenas para as doenças cardiovasculares. 0 carcinoma de Walker-256 é um tumor especifico de ratos considerado modelo experimental de caquexia, por demonstrar crescimento tumoral bastante acelerado, e consequentemente levando a caquexia e a morte rapidamente dos animais. Assim, esse trabalho tem como objetivo comparar a evolução tumoral em ratos, implantados com carcinoma de Walker 256, em diferentes locais de desenvolvimento, para analisar os efeitos dessa evolução tumoral e consequentemente sobre as respostas do hospedeiro.

\section{Resultados e Discussão}

Ratos Wistar machos foram distribuídos em quatro grupos - controle $(\mathrm{C} ; \mathrm{n}=3)$, e após contagem do número, injetou-se $0,4 \mathrm{~mL}$ de suspensão contendo $5 \times 10^{6}$ células viáveis do tumor de Walker nos animais experimentais perfazendo os grupos: intraperitônio (IP; $n=6)$, subcutâneo (SC; $n=6)$ e intramuscular (IM; $n=6)$, para analisar os mecanismos de resposta desses hospedeiros quanto a evolução de peso corporal e peso relativo dos órgãos e tecidos (fígado, musculo, coração, adrenal e tumor). O presente trabalho mostra apenas a evolução e resultados do grupo implantado com tumor intraperitônio.

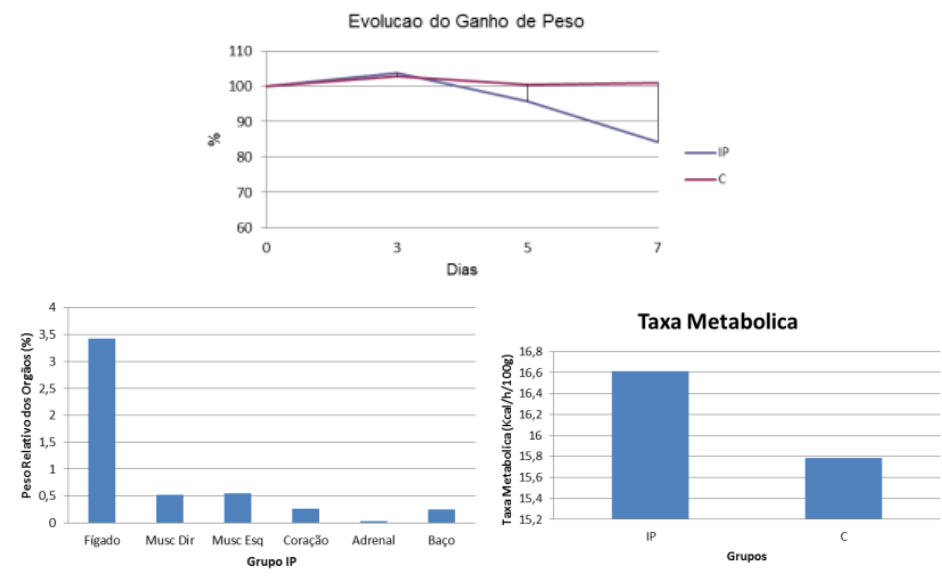

Figura 1 - Curva de evolução do ganho de peso (\%) ao longo ao longo do experimento, porcentagem do peso relativo dos órgãos e taxa metabólica dos animais com tumor IP em relação aos animais controles $\mathrm{C}$.

\section{Conclusões}

Os sintomas verificados foram realmente aqueles esperados como aumento do volume abdominal e a bolsa escrotal hemorrágica, pelos arrepiados, palidez, anemia e icterícia. $\mathrm{O}$ ganho de peso dos IP seguiu constante nos primeiros dias, porém houve drástica perda de peso em comparação ao grupo C, associado ao crescimento do tumor. A taxa metabólica do IP foi elevada mostrando intenso dispêndio energético para manutenção do crescimento das células tumorais e também do hospedeiro.

Agradecimentos

Profis,

FAPESP;

CNPq-PIBIC/UNICAMP 